\title{
Welsh plans to tackle obesity will improve oral health
}

Government plans to reduce obesity amongst the population in Wales could mean various steps that will also improve oral health, especially that of children.

On 17 January 2019, the Welsh Government published a consultation $^{1}$ on a plan to combat what it called the greatest public health challenge facing Wales - obesity.

The consultation called Healthy Weight: Healthy Wales outlines the actions to be taken to help people in Wales maintain a healthy weight.

The UK has one of the highest levels of obesity in Western Europe and in Wales, $27 \%$ percent of four- to five-year-olds and $60 \%$ of adults are overweight, which raises the risk of developing serious health conditions such as coronary heart disease, type 2 diabetes and some cancers.

The proposals set out in the consultation focus on prevention and are supported by research and international evidence from Public Health Wales into what can help people be a healthy weight.

One of the consultation's themes is to have 'healthy settings', meaning that education, work and leisure facilities should promote and provide opportunities for people to access healthy meals, snacks and drinks and be physically active as well as enabling school settings to have healthy eating and daily physical activity opportunities.

Encouraging children to consume less sugar-rich food and drink would also lead to improved oral healthcare.

The Welsh Government is keen to create environments that help people make healthier food choices and create opportunities in daily life for people to be active.

This could include legislating on price promotions, calorie labelling on foods eaten out of the home, banning the sale of energy drinks to children and bringing together various programmes to develop active environments across communities.

Welsh Health Minister Vaughan Gething said: 'Too many people in Wales are overweight or obese. Our high rates of overweight four- to five-year-olds is a matter of national concern. This government is not prepared to let a poor diet or physical inactivity be defining features in the lives of our children and young people.

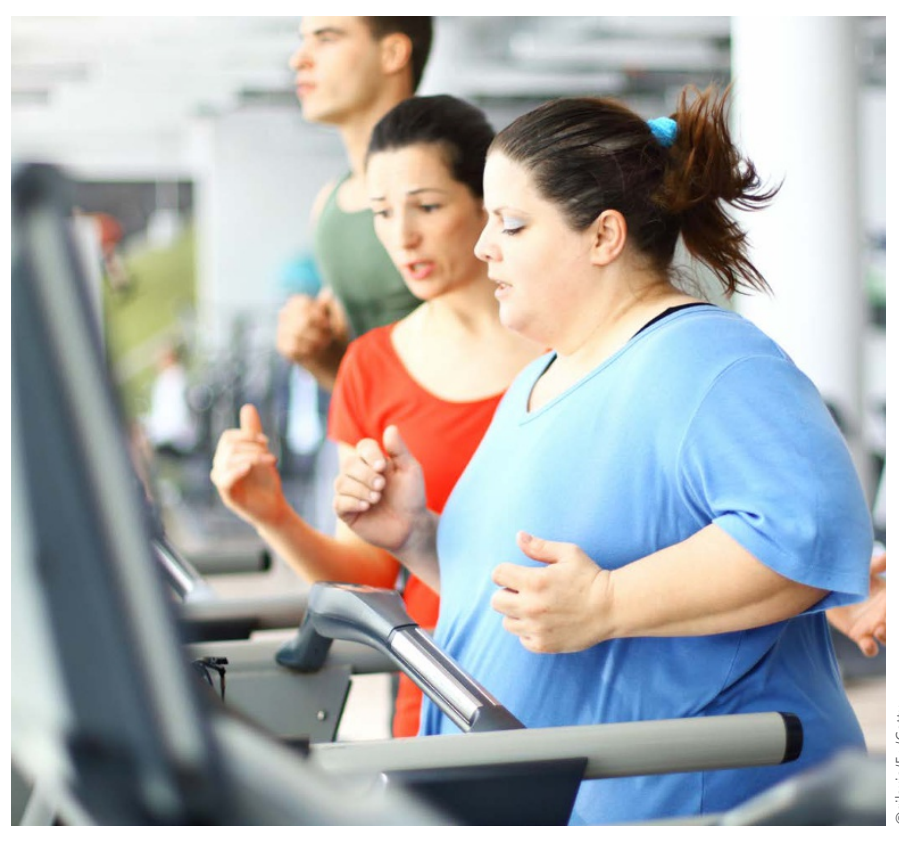

'We know that many of us want to eat healthier or do more exercise. However, fitting this into our busy lives can appear to be an overwhelming challenge. Creating an environment where it is normal and easy for us all to eat well and be physically active can make a significant difference and nudge us to change our daily routines.

'We want to encourage people to manage their own health and well-being, to lose weight and to be active. The long term sustainability of the NHS is at stake. We want people in Wales to have long, healthy, happy lives. Being a healthy weight is a central part of achieving that goal.'

The consultation closes on 12 April 2019.

Welsh Government. Healthy Weight: Healthy Wales. 2019. Available at https://beta.gov. wales/sites/default/files/consultations/2019-01/consultaton-document_0.pdf (accessed January 2019).

\section{Chance to reunite with classmates}

King's College London is holding its Dental Alumni Weekend 2019 on 1 and 2 March 2019, billed as high quality continuing professional development alongside opportunities for alumni, staff and friends of the Faculty to get together.

On the first day, people attending can choose between the John McLean Symposium featuring national and international speakers sharing their '20/20' Vision of Restorative Dentistry, or the Hygienists' and Therapists' Specialist Section Meeting.

These will be followed by the SPS Staff and Alumni Drinks Reception and Annual Dental Dinner, held in the Robens Suite at the top of Guy's Tower in London. There is an optional black tie dress code and guests and partners are welcome.
On the second day, a Clinical Open Day will take place in Guy's Tower and this year's programme includes keynote lectures in memory of Professor Rod Cawson and Professor Walter Herbert,

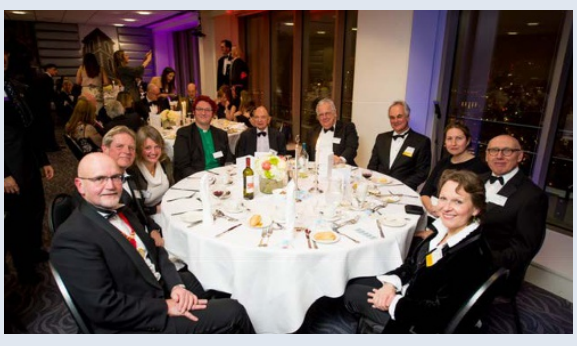
an opportunity to hear about the newly re-structured 'faculty', tours of recently refurbished clinical teaching facilities and hands-on workshops.

The Dental Alumni Association will also be holding its Annual General Meeting to which all alumni are invited. This will be followed by the Executive Dean's Lunch hosted by Professor Mike Curtis.

More information is available at https:// www.eventbrite.co.uk/e/kings-college-london-dental-alumniweekend-2019-tickets-53145046264 or by mailing reunions@kcl. ac.uk or calling 02078483053 . 